\title{
ON THE ACCURACY IMPROVEMENT IN ULTRASONIC INSPECTION BY USING COMPUTER GRAPHICS AND WAVEFORM ANALYSIS
}

\author{
Noboru SUGAWARA*, Toshiyuki OSHIMA**, \\ Shuichi MIKAMI*** and Shinya SUGIURA****
}

\begin{abstract}
The C-scan images of defects made by drilled holes with different types are obtained and the effect of length and inclination of drilled holes on the images are discussed in this paper. The artificial cylindrical defect of diameter $1 \mathrm{~mm}$ and $2 \mathrm{~mm}$ were made in a steel plate specimen of $9 \mathrm{~mm}$ thick and 3D images of these defects are obtained by using a graphic software on a workstation from the maximum amplitude data and path length data of received waves. In the detail waveform analysis of boundary and bottom echo the method to get more accurate size of defect are shown. And in order to apply C-scan ultrasonic test to a field inspection the effect of surface roughness and thickness of specimen on their images are analyzed and the modified immersion method to use a small water bag between a probe and a specimen are proposed.
\end{abstract}

Keywords : ultrasonic inspection, computer graphics, 3D image, NDE

\section{INTRODUCTION}

When we diagnose the structural integrity of a steel member in service and evaluate its remaining life time, we need to improve analyzing method to get the accurate information of a internal defect of a member. And by the recent demand for high level quality control of welding of steel joint the accuracy improvement of defect detection in the image display became essential in nondestructive evaluation $(\mathrm{NDE})^{1)-3)}$. So far the defect information obtained by an ultrasonic test is displayed in several ways and A-scan and B-scan displays are commonly used in a field inspection and C-scan display is mostly used in laboratory test of the steel structural member ${ }^{4), 5)}$.

In this study we made the different types of artificial defects by drilled holes in a steel plate specimen to be observed by an ultrasonic scanning pulse echo test. And the several effects of measurement condition on the display image are obtained by this experimental analysis ${ }^{6,7)}$. The artificial drilled holes with diameter $1 \mathrm{~mm}$ and $2 \mathrm{~mm}$ are made with different lengths and inclinations and the graphic images are compared among these cases. 3D images of these defect are obtained by a

* Member of JSCE, Associate Professor, Department of Civil Engineering, Kitami Institute of Techonology

(165 Koen-cho, Kitami, Hokkaido)

** Member of JSCE, Dr.Eng., Professor, Department of Development Engineering, Kitami Institute of Techonology

*** Member of JSCE, Research Associate, Department of Development Engineering, Kitami Institute of Techonology

**** Member of JSCE, Research Engineer, Konoikegumi Corporation graphic software ${ }^{8)}$ on a workstation by using the maximum amplitude data of boundary and bottom echo and path length data by which we find from where the incident wave returned back. And in order to apply the C-scope immersion method of ultrasonic test to a field inspection, the effects of surface roughness and the thickness of specimen are analyzed, and also the simple method not to use a water tank but to use a small water bag between a probe and a specimen are used to get the same Cscan image of immersion test. The accurate defect size obtained by the ratio of the maximum amplitudes between the boundary echo and bottom echo are shown in the detail waveform analysis of the reflection wave.

\section{MEASUREMENT SYSTEM}

The measurement system employed in this study is shown in Fig.1. This system of immersion type ultrasonic testing can be illustrated by the several parts of subsystem and these subsystems are

(1) Image display system

a) ultrasonic transducer

b) automatic scanning controller

c) amplitude sampler of ultrasonic wave

d) image display computer

(2) Ultrasonic wave recorder system

Main functions of this system are automatic scanning control, ultrasonic acquisition and image display and their datails are as follows :'

1) Ultrasonic transducer (normal transducer of focussed type) of immersion testing

a) frequency of transducer

$5 \mathrm{MHz} \quad 10 \mathrm{MHz} \quad 25 \mathrm{MHz}$

b) approximate focal length in water

$50 \mathrm{~mm} \quad 40 \mathrm{~mm} \quad 20 \mathrm{~mm}$

2) Automatic scanning control system 


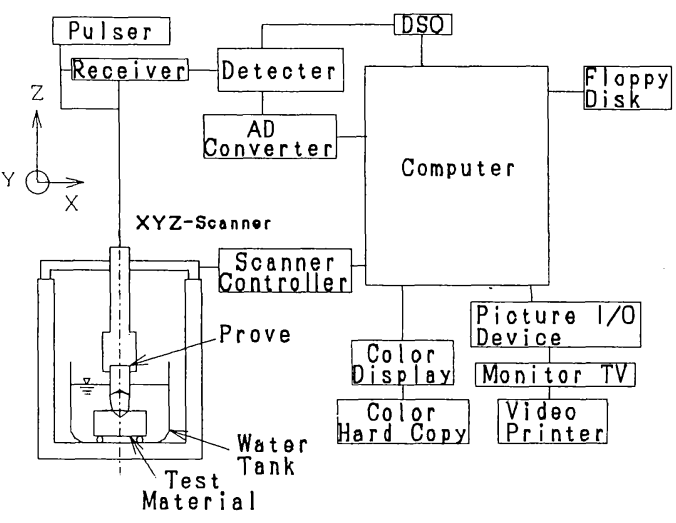

Fig.1 Measurement system

(3D rectangular coordinates)

a) scanning range $(\mathrm{mm})$

$500(\mathrm{~W}) \times 600(\mathrm{~L}) \times 250(\mathrm{D})$

b) scanning pitch (variable, $\mathrm{mm}$ ) $0.05 \sim 9.95$

c) scanning speed $10 \sim 150 \mathrm{~mm} / \mathrm{sec}$ (automatically given correspond to scanning pitch)

3) Image display system (C-scope)

a) 256 gradations of monochrome between white and black

b) 16 gradations of color level

4) Ultrasonic wave recorder system

(Digital storage oscilloscope)

a) sampling speed

500 Mega samples per second

b) resolution of amplitude $10 \mathrm{bit}$

c) frequency range up to $300 \mathrm{MHz}$

d) option for FFT

The sampling gate of time axis is set correspond to the thickness of specimen to receive first boundary echo from a defect and bottom echo. Data of maximum amplitude of each echo waves which passed above sampling gate are obtained as a digital value of a voltage by a translation of analogue signal. $\mathrm{v}^{\gamma} \mathrm{e}$ get its changes of the maximum amplitude correspond to the shape and thickness of a defect. Comparison of this digital voltage data with the reference voltage gives us image data to represent the 2D shape of defect on the screen. Ultrasonic wave recorder system can get the whole reflection waves that passed above mentioned time gate as 4096 data of digital values for every wave and display the spectrum of the detected waves by FFT.

\section{DETECTED IMAGE OF DEFECT SHAPE}

When we detect a defect shape by using ultrasonic testing, the accuracy of image data of a detected defect depends upon the resolvability of
Table 1 Specimens

\begin{tabular}{|c|c|c|c|c|c|}
\hline Type I & $\phi\left({ }^{\circ}\right)$ & $\mathrm{h}(\mathrm{mm})$ & Type II & $\phi\left(^{\circ}\right)$ & $h(\mathrm{~mm})$ \\
\hline$A$ & \multirow{3}{*}{90} & 5 & $\mathrm{~J}$ & \multirow{3}{*}{$\begin{array}{ll}9 & 0\end{array}$} & 5 \\
\hline B & & 3 & $\mathrm{~K}$ & & 3 \\
\hline C & & 2 & $\mathrm{~L}$ & & 2 \\
\hline $\mathrm{D}$ & \multirow{3}{*}{75} & 5 & & & \\
\hline E & & 3 & & & \\
\hline $\mathrm{F}$ & & 2 & & & \\
\hline G & \multirow{3}{*}{60} & 5 & & & \\
\hline $\mathrm{H}$ & & 3 & & & \\
\hline I & & 2 & & & \\
\hline
\end{tabular}

positioning and inclination of transducer during the measurement. It is important to employ a good system to improve the accuracy. What we discuss here is to analyze ;

a) the effect of ultrasonic wave scattering at the boundary of a defect and the coupling effect of two close defects on the image

b) the effect of depth and inclination of drilled holes in the specimen

c) the effect of frequency of transducer on the image data

After the comparison of resolution of image data obtained by three transducer of different natural frequencies we decided to use the transducer mostly with $10 \mathrm{MHz}$ frequency in this research.

\section{(1) Specimen and measurement}

In the steel plate specimen with $9 \mathrm{~mm}$ thick twelve artificial defects of different types are made by drilled holes as shown in Table 1. Among them there are three types of depth $h$ as $5 \mathrm{~mm}, 3 \mathrm{~mm}$, $2 \mathrm{~mm}$ and three types of inclinations $\phi$ as $90^{\circ}, 75^{\circ}$, $60^{\circ}$ of drilled holes, respectively. And the diameters of drilled holes are $2 \mathrm{~mm}$ and $1 \mathrm{~mm}$ as shown in Table 1 and two close holes of diameter $1 \mathrm{~mm}$ at $2 \mathrm{~mm}$ distant are used to get the coupling effect of ultrasonic scattering on the image of defect.

The kinds of the specimen for coupling effect are named by specimen J, K, L with different depth as $5 \mathrm{~mm}, 3 \mathrm{~mm}, 2 \mathrm{~mm}$ as shown in Table 1 , respectively. Reflection waves from the defect are measured by using a line scanning along with a distinct line to across the C-scan image of defect. They are discussed later.

Data of maximum amplitudes of bottom echo and boundary echo passed through the time gate for each scanning point are used to display a C-scan image on the screen. This set of data for C-scan image is called "maximum amplitude data" in this paper. Data of path length between incident point and where the detected boundary echo returned back are also used to find out the depth of the defect. This set of data of path length is called "path length data" and obtained at each scanning point. 


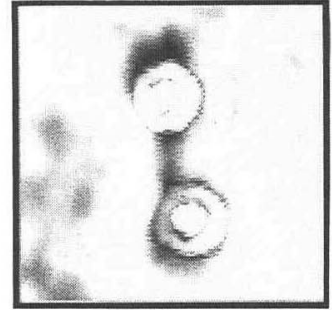

Fig.2 C-scan image of specimen $\mathrm{K}$

$(6 \times 6 \mathrm{~mm}$, pitch $0.05 \mathrm{~mm}$, scale $\longmapsto 0.8 \mathrm{~mm}$ )

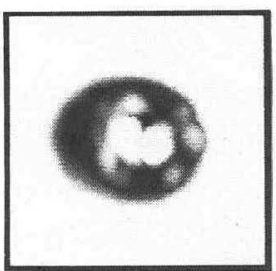

Fig.4 C-scan image of specimen D

$(5 \times 5 \mathrm{~mm}$, pitch $0.05 \mathrm{~mm}$, scale $\longmapsto 0.8 \mathrm{~mm})$

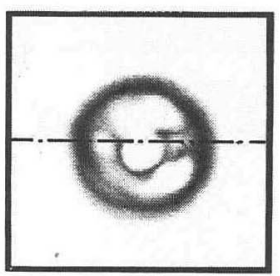

(a) Maximum amplitude data

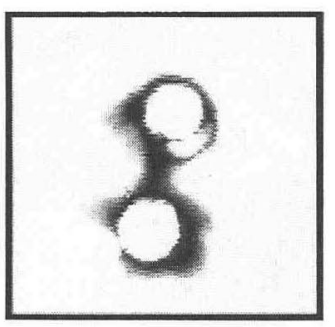

Fig.3 C-scan image of specimen $\mathrm{J}$

$(6 \times 6 \mathrm{~mm}$, pitch $0.05 \mathrm{~mm}$, scale $-0.8 \mathrm{~mm}$ )

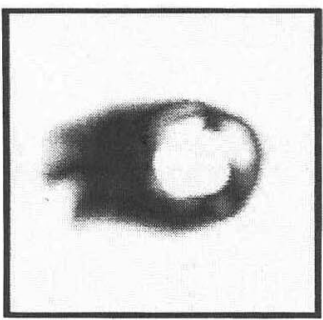

Fig.5 C-scan image of specimen $G$

$(6 \times 6 \mathrm{~mm}$, pitch $0.05 \mathrm{~mm}$, scale $\longmapsto 0.8 \mathrm{~mm}$ )

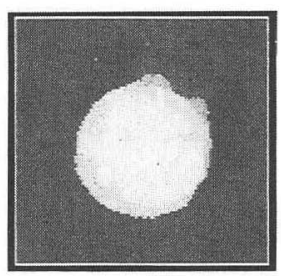

(b) Path length data
Fig.6 Images of maximum amplitude data and path length data for specimen A $(5 \times 5 \mathrm{~mm}$, pitch 0.05 $\mathrm{mm}$, scale $\longmapsto 0.8 \mathrm{~mm}$ )

\section{(2) Results of display image}

The $\mathrm{C}$-scan image of defect $\mathrm{K}$ and $\mathrm{J}$ with different depth obtained by using the transducer with $25 \mathrm{MHz}$ are shown in Fig.2 and Fig.3, respectively. The tip shapes of drilled holes are well detected and the resolution of image for defect $\mathrm{J}$ is rather poor than that for defect $\mathrm{K}$. The focal point of the ultrasonic waves is adjusted around at the tip of drilled hole in this measurement. If the depth of drilled hole is deep, that is, the distance between the defect tip and bottom of plate is large, the scattering effect of ultrasonic wave on the display image of the defect becomes to be larger than the others. This behavior of wave scattering and the decrease of resolution is considered somewhat like that the dim resolution of a photo is obtained by a insufficient exposure depth of a camera.

The coupling effect of two close defects of small size does not effect on their image in this case. By the comparison of defect image with different frequencies of transducers it is considered that a good result of display image of defect shape is obtained by the transducer with higher frequency. However the focal length of the transducer with high frequency is so small that the transducer with $10 \mathrm{MHz}$ is considered to be suitable to use for the inspection of steel structure. The effect of shape and inclination of the defect on the display image is not observed in this case and good resolutions of the images are obtained for each case of defect types. The display images for the defect D and $G$ of inclined drilled holes are shown in Fig.4 and Fig.5, respectively. By the comparison of the image results between the defect A as shown in Fig.6(a) and the defect $\mathrm{D}$ and $\mathrm{G}$ with different inclinations of the drilled holes, it is seen that the amplitude of boundary echo becomes small. However good resolution of display image for each defect types are obtained by this system of measurement. And by the comparison of the maximum amplitude data with the path length data as shown in Fig.6(a), (b) for defect $A$, the accurate depth of the defect is given. It is discussed in the next chapter by using computer graphics.

\section{3D DISPLAY OF DEFECT SHAPE BY MAXIMUM AMPLITUDE DATA AND PATH LENGTH DATA}

As mentioned before, by using ultrasonic inspection system we can obtain the maximum amplitude data which represent the distribution of maximum amplitude of echo waves reflected from the bottom of the plate or boundary of the defect and the path length data which represent from where the incident wave returned back. And with these data we can get the C-scan images of maximum amplitude and path length with 256 grades of color display on $2 \mathrm{D}$ rectangular coordinate.

In this chapter 3D representation of maximum amplitude data by using a computer graphics (CG) software on a workstation (WS) is shown. In this analysis the values of 256 color grades correspond to the amplitude which are on the 2D plane of scanning range are taken in the vertical coordinate perpendicular to the above 2D plane. And the path length data are used like filtering of the boundary echo waves by which we can pass the boundary echo waves through to separate from the bottom echoes within the scanning range. By this filtering technique we can get the clear 3D images of maximum amplitude data by representing the clear 


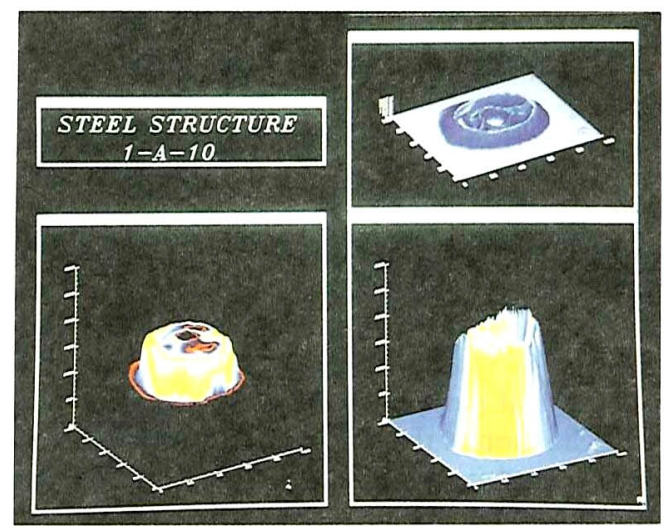

(a)

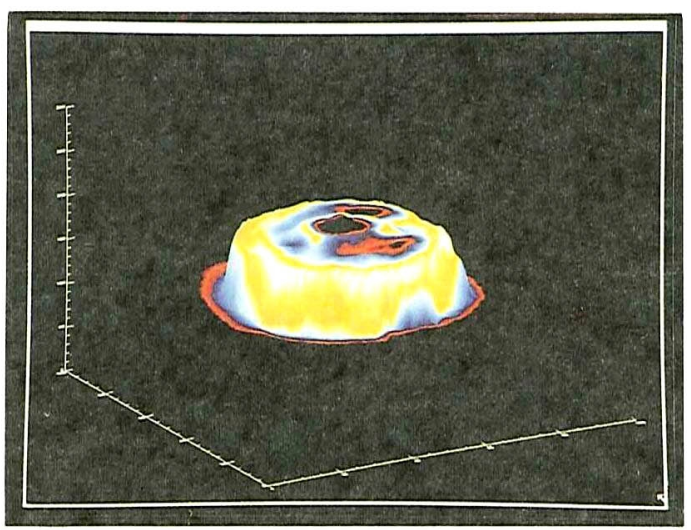

(b)

Fig.7 3D images of specimen A

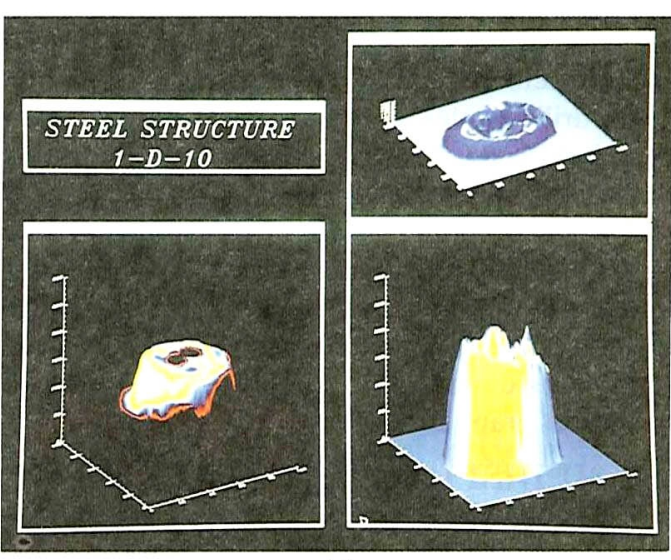

(a)

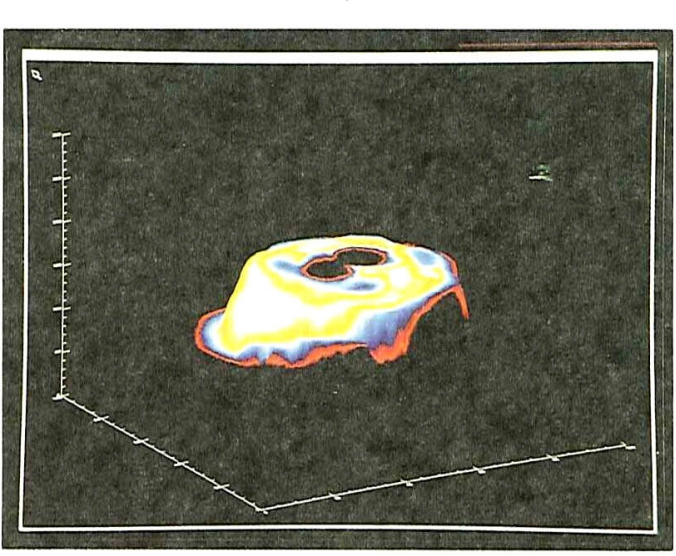

(b)

Fig.8 3D images of specimen D

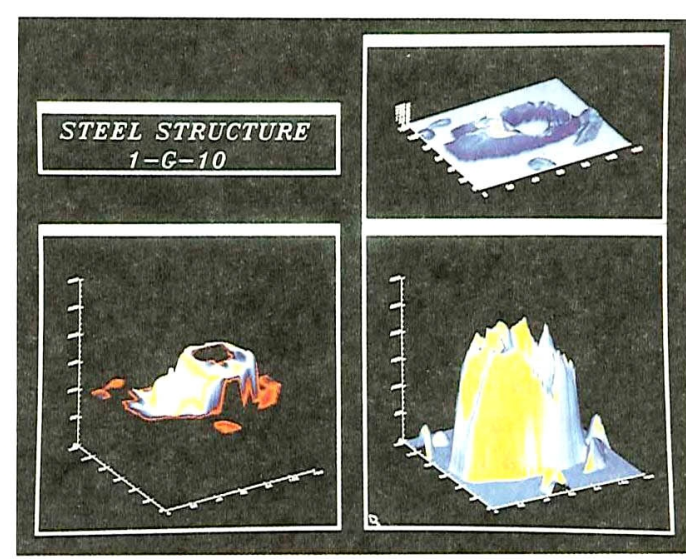

(a)

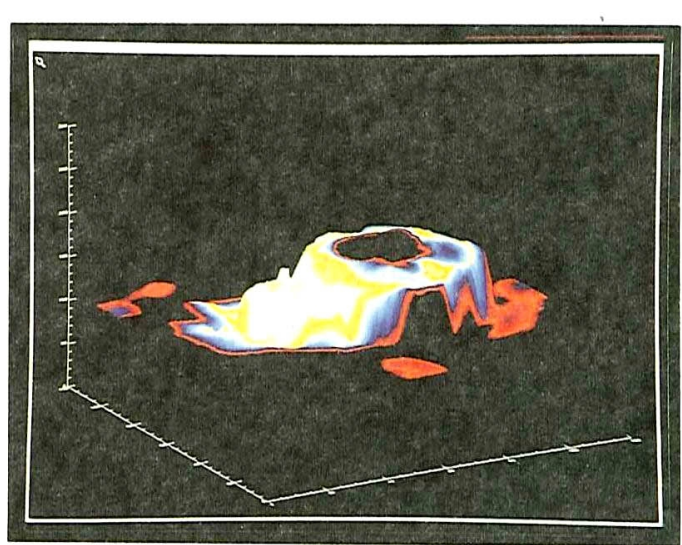

(b)

Fig.9 3D images of specimen G

boundary of small defect.

In Fig.7(a) three different 3D images of defect type $\mathrm{A}$ as listed in Table 1 are shown. In the lower picture of right hand side in Fig.7(a), the above mentioned $3 \mathrm{D}$ representation of the maximum amplitude data by converting the 256 color grades values to the vertical coordinate values within the scanning range is shown by using CG software on the WS display. In the upper picture of right hand side in Fig.7(a) the different representation of the 


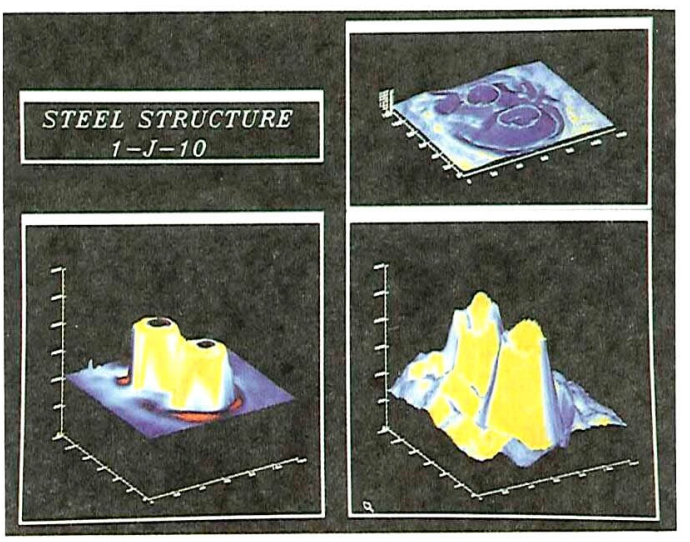

(a)

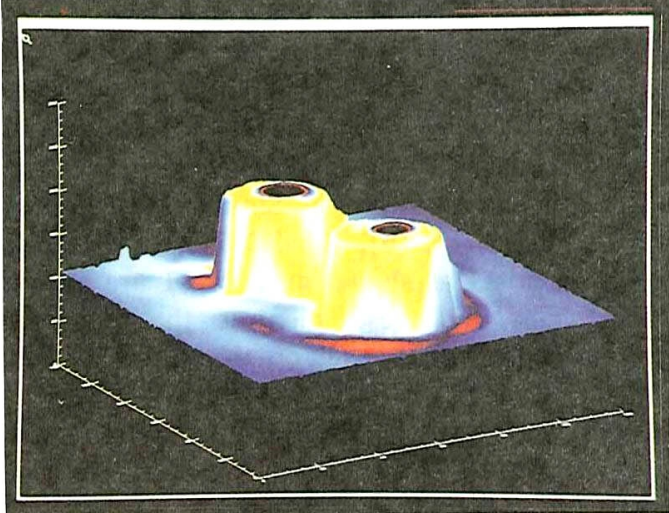

(b)

Fig.10 3D images of specimen J

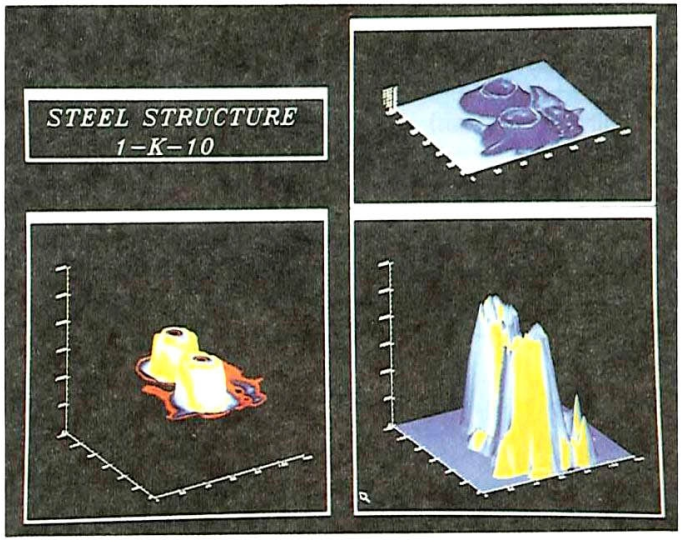

(a)

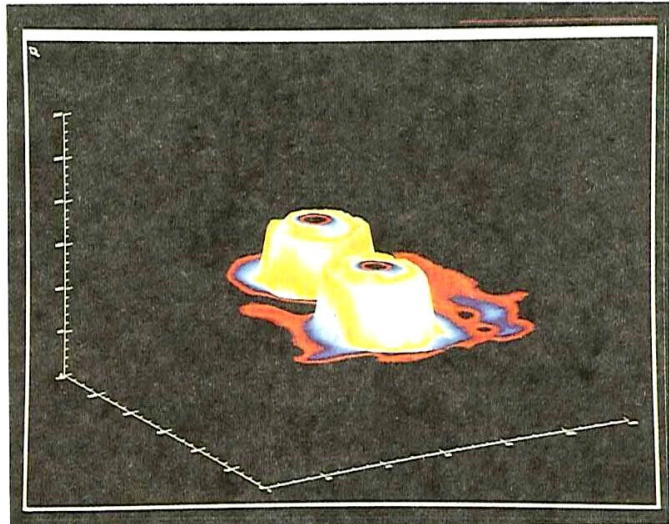

(b)

Fig.11 3D images of specimen $\mathrm{K}$

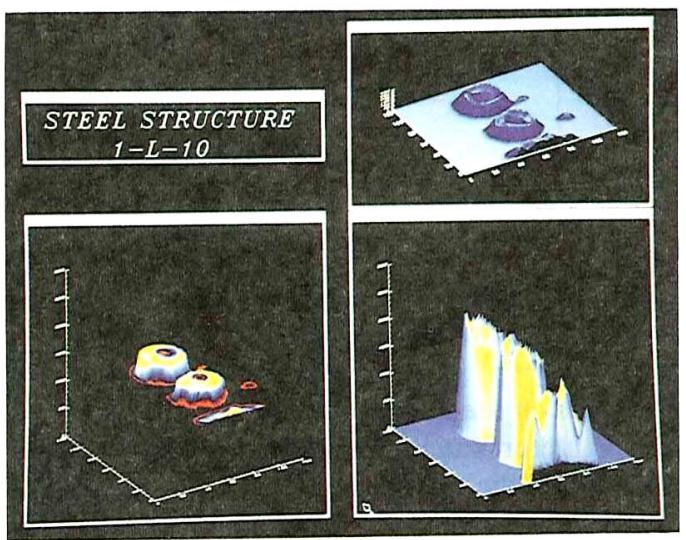

(a)

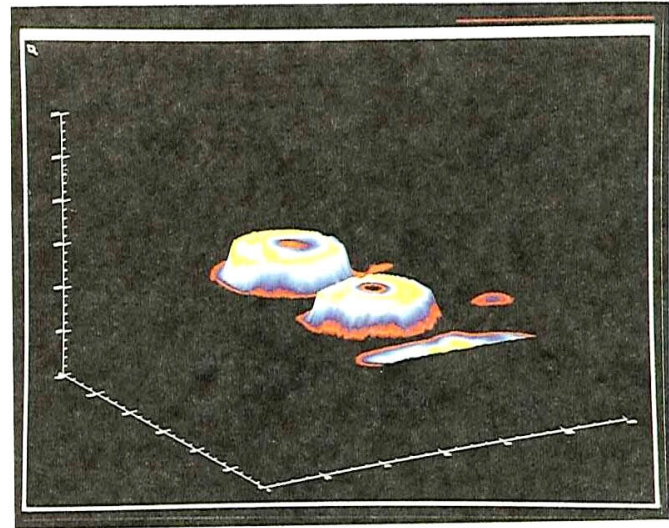

(b)

Fig.12 3D images of specimen $\mathrm{L}$

same 3D image as mentioned above is shown by changing the location of view point and the scale of vertical coordinate on CG software. By this picture we can find out the detailed undulation of small defect tip by clear image. In the lower picture of left hand side in Fig.7(a) only the 3D image of a defect shape is shown in the dark background by using the path length data to pass only the boundary echo values by an above mentioned filtering technique. 
In Fig.7(b) the enlarged picture of the same defect as shown in Fig.7(a) is shown. And by using $3 \mathrm{D}$ rotation procedure on CG software we can rotate the 3D image of the defect on the display of WS we can understand the whole shape of a small defect by 3D representation. Similarly in Fig.8(a), (b), and Fig.9(a), (b), the 3D images of defect types $D$ and $G$ as shown in Table 1 are shown, respectively. By these pictures the effect of inclination of drilled holes on the 3D images are clearly obtained. And in Fig.10(a), (b), Fig.11(a), (b), and Fig.12(a), (b), the 3D images of the defect types $\mathrm{J}, \mathrm{K}$ and $\mathrm{L}$ are shown, respectively. The depths of the two close drilled holes are smaller in the order of $\mathrm{J}, \mathrm{K}$ and $\mathrm{L}$ as $5 \mathrm{~mm}, 3 \mathrm{~mm}$ and $2 \mathrm{~mm}$, respectively. By using this CG technique to obtain 3D images of defects we can find out the detailed structure of a defect and thus evaluate the accurate strength of a material. It is called a "D-scope display" of a defect correspond to the A-scope, Bscope and C-scope display.

\section{APPLICATION OF C-SCAN DISPLAY TO THE FIELD INSPECTION}

\section{(1) Effect of surface roughness on the C-scan image analysis}

In order to investigate the scattering effect due to surface roughness of a specimen on the accuracy of the defect detection, the grains of sand are spread on the steel plate of $6 \mathrm{~mm}$ thick and the artificial surface roughness with small amplitude is made on the upper surface of the specimen. The drilled hole of diameter $4 \mathrm{~mm}$ and length $3 \mathrm{~mm}$ are made on the lower surface of the specimen.

The grain sizes of sand are $0.15 \mathrm{~mm}, 0.2 \mathrm{~mm}$ and $0.3 \mathrm{~mm}$ for three different specimens, respectively, and the power spectrum of surface roughness in the case of grain size $0.3 \mathrm{~mm}$ are shown in Fig.13. This results obtained by the equipment for surface roughness which can scan on the area of artificial defect by $0.1 \mathrm{~mm}$ pitch. The amplitudes of surface roughness of 101 points over the area of $10 \mathrm{~mm} \times$ $10 \mathrm{~mm}\left(100 \mathrm{~mm}^{2}\right)$ are obtained in this case by 11 lines of equal distance and analyzed by FFT spectrum software. The result shown in Fig.13 is the average power spectrum of surface roughness by the above 11 lines of equal distance over the defect.

The straight line is given by

$$
S=a \Omega^{-n}
$$

where $S=$ power spectrum of surface roughness $a, n=$ parameters for surface roughness $\Omega=$ frequency of surface roughness

The results of parameters $a, n$ for three cases of surface roughness are shown in Table 2 . The defect

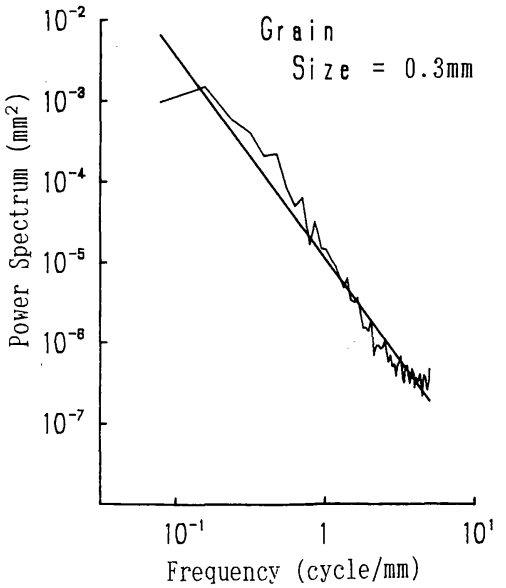

Fig.13 Power spectrum of surface roughness

Table 2 Results of parameters $a, n$

\begin{tabular}{|c|c|c|}
\hline Grain size $(\mathrm{mm})$ & $\mathrm{a}\left(10^{-6}\right)$ & $\mathrm{n}$ \\
\hline \hline 0.15 & $1 \sim 4$ & 2.3 \\
\hline 0.20 & $5 \sim 10$ & 2.4 \\
\hline 0.30 & $7 \sim 13$ & 2.3 \\
\hline
\end{tabular}

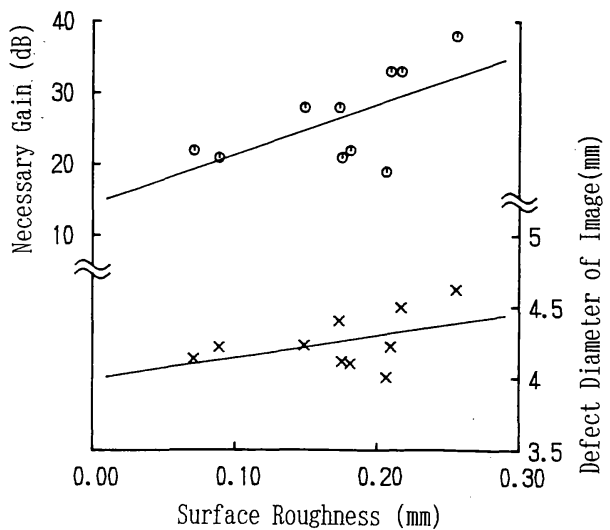

Fig.14 Scattering effect by sand on steel surface (Grain size is $0.3 \mathrm{~mm}$ )

diameters on the detected images of drilled hole of real diameter $4 \mathrm{~mm}$ and necessary gain values of amplifier of the system in the case of grain size of $0.3 \mathrm{~mm}$, are shown in Fig.14. The abscissa of this figure is root mean square of surface roughness. The values shown by the mark $X$ and scaled by the ordinate of right hand side correspond to the results of detected diameters of drilled hole. If the surface roughness becomes large, we need to choose the large gain value for amplification of the measurement. However when we use large amplification, we loose $\mathrm{SN}$ ratio at the measurement. 


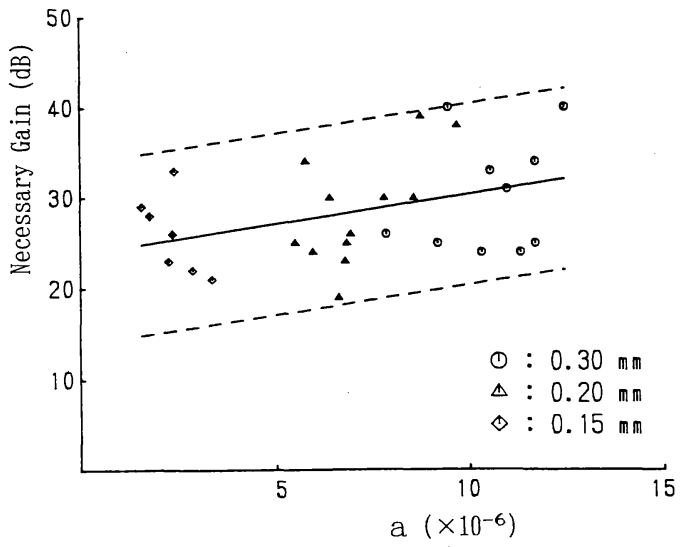

Fig.15 Relation of necessary gain and parameter $a$

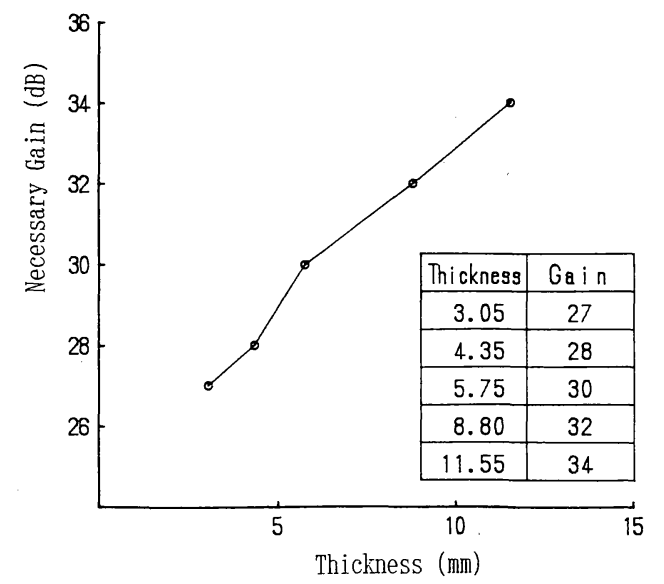

Fig.16 Relation of steel thickness and necessary gain (For bottom echo)

Thus the necessary gain values chosen to detect by a good defect images depending on the surface roughness exist which are shown by the mark $\bigcirc$ and scaled by the ordinate of left hand side in Fig.14. We can find in Fig.14 that if the surface roughness becomes large, detected sizes of defect images become scattered by large variance and the defect is detected by larger sizes. And again necessary gain values to be used depending on the condition of surface roughness of the specimen are given in Fig.14. The variation range of necessary gain values to be chosen as a function of parameter a of power spectrums of surface roughness are shown in Fig.15, and the necessary gain values are given by the range from $20 \mathrm{~dB}$ to $40 \mathrm{~dB}$. Thus we can find out an appropriate gain value in the field test depending on the surface roughness of the structural member.

(2) Effect of thickness of specimen on the image

Because of the thickness of specimen the

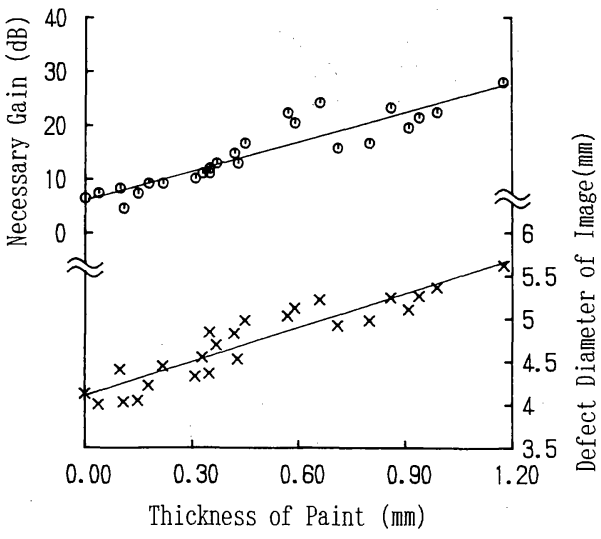

Fig.17 Effect of paint on steel surface

attenuation effect on the ultrasonic echo is essential and necessary to have data to choose an appropriate frequency of probe and an amplifying gain value at a measurement. To obtain a relationship between a necessary gain value and a thickness of specimen, five specimens of defferent thickness by $3.05 \mathrm{~mm}, 4.35 \mathrm{~mm}, 5.75 \mathrm{~mm}, 8.80 \mathrm{~mm}$ and $11.55 \mathrm{~mm}$ are used in this experiment. Each specimen has a drilled hole of same diameter $4 \mathrm{~mm}$ and different length. The length of drilled hole is made approximately a half of thickness of specimen and they are $1.53 \mathrm{~mm}, 2.18 \mathrm{~mm}, 2.88 \mathrm{~mm}, 4.40 \mathrm{~mm}$ and $5.78 \mathrm{~mm}$, respectively. The necessary gain values to get -a good result of image are increased by a function of thickness of specimen as shown in Fig.16.

\section{(3) Effect of paint on the specimen}

As a field inspection by $\mathrm{C}$-scan method we have to measure a structural member through the layered paint. If the thickness of paint is thick, because of a damping effect we have to choose a necessary gain to get a accurate image of the defect. The 26 specimens with different thickness of paint and with the drilled holes of same diameter $4 \mathrm{~mm}$ are used. The defect size of detected images as a function of paint thickness are plotted by the mark $\times$ and scaled by the ordinate of right hand side in Fig.17. And if the paint thickness becomes thick, the necessary gain value (shown by mark $\bigcirc$ ) to get a good image of defect becomes high, and then the defect diameter of detected image becomes larger than the real diameter $4 \mathrm{~mm}$ as shown in Fig.17.

(4) Experiment of a modified method for immersion field testing

In the case by immersion ultrasonic testing we can obtain more accurate image of defect by using higher frequency of probe than a direct scan method. As we, however, have to put the specimen 


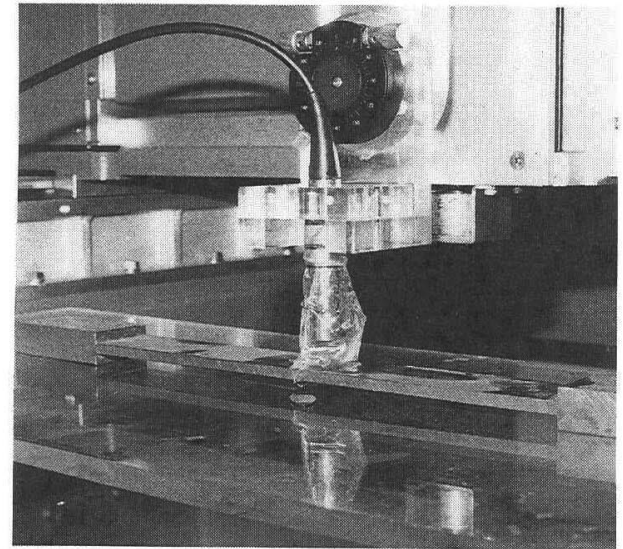

Fig.18 A probe with a water bag in Case(b)

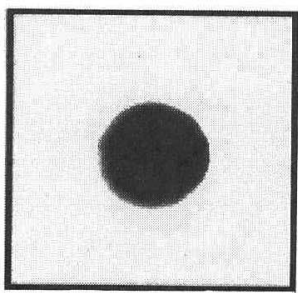

Case (a)

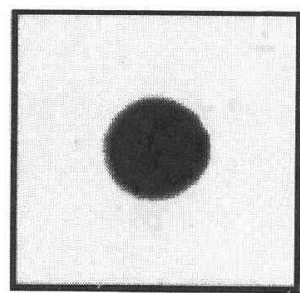

Case (b)

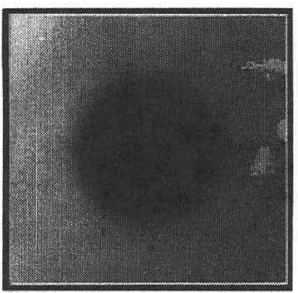

Case (c)

Fig.19 C-scan images by three testing methods $(10 \times 10$ $\mathrm{mm}$, pitch $0.05 \mathrm{~mm}$, scale $\longmapsto 1.6 \mathrm{~mm}$ )

in the water tank, it is difficult to apply the same method of C-scan testing for a field inspection. We need to develop another method not to use the water tank at the field inspection. Thus in this study we tried to test and compare two other methods with a usual immersion method. The specimen is a steel plate of $6 \mathrm{~mm}$ thick and has a drilled hole of diameter $4 \mathrm{~mm}$ and length $3 \mathrm{~mm}$ from the bootom surface. Three different testing methods are

Case(a) : usual immersion test,

Case(b) : test by a probe with a water bag between a probe and specimen(as shown in Fig.18), and

Case(c) : test by using a grease layer between a probe and specimen

and the detected images obtained by these three methods are compared in Fig.19. The other parameters are same in all cases. It is found from these results that by using the method of Case(b) we can obtain the same defect image as that by Case(a) and by the method of Case(c) the image may become fuzzy and then be obtained by large diameter of detected image.

\section{ACCURATE ANALYSIS OF BOUND- ARY ECHO BY WAVE ANALYSIS}

The detected defect image measured by ultrasonic scanning test is given by the data of echo amplitude. The echo amplitude data consist of the maximum amplitude of boundary and bottom echo which are reflected from the boundary of a defect and lower surface of the specimen. If the location of probe and the focal point of the incident wave reaches to the boundary of the defect, the boundary echo reflected from the boundary of the defect is detected together with the bottom echo reflected from the lower surface of the specimen within the time gate set up by the system. However we sometimes cannot obtain a good defect image with sufficient accuracy in these measurement because of the wave scattering at the boundary of the defect. This scattering effect on the wave reflection depends upon the wave length and shape and size of a defect. Therefore we need a detail analysis of the boundary echo to get the accurate information from the wave on the shape and size of the defect in addition to the $\mathrm{C}$-scan image given by the echo amplitude data.

In this chapter we discuss the precise wave analysis of boundary echo obtained within the time gate set up by the system and find out a method to measure the more accurate size of the defect.

\section{(1) Experimental measurement}

The circular drilled holes of diameter $2 \mathrm{~mm}$ are made in the steel plate of $9 \mathrm{~mm}$ thick with three different lengths of $5 \mathrm{~mm}, 3 \mathrm{~mm}$ and $2 \mathrm{~mm}$ and we call here these specimen as specimen A, B and C, respectively. The focus of the probe is first adjusted at the center of drilled hole. And the probe with $10 \mathrm{MHz}$ resonance frequency scans over the square of the area of $5 \mathrm{~mm} \times 5 \mathrm{~mm}$ on the drilled hole to get the C-scan image of the defect. The reflection waves are received along with the line shown in Fig.6(a) by the chained line by $50 \mu \mathrm{m}$ pitch around the boundary of the defect and by $100 \mu \mathrm{m}$ pitch for the other area. The reflection waves are transformed to the digital data by using the digital storage oscilloscope (DSO) and stored to a floppy disk. The sampling pitch of time is $0.57 \mathrm{nsec}$ and the number of data for the one reflection wave is $\mathbf{4 0 9 6}$ points.

In Fig.20(a), (b) the typical original data received by the ultrasonic scanning test are shown. 


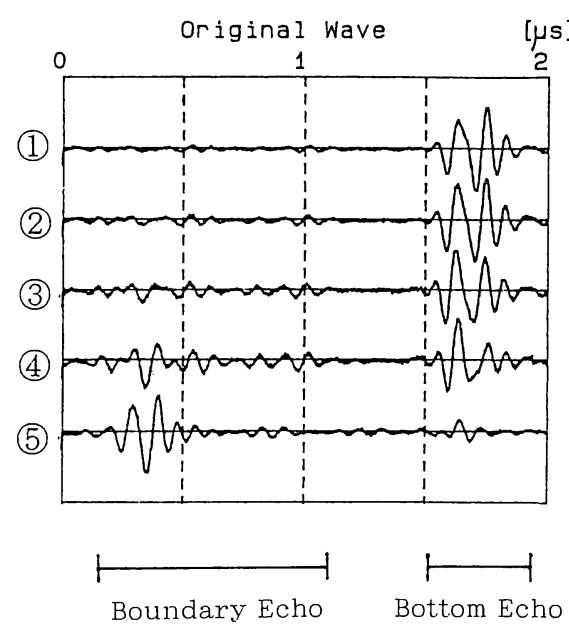

(a)

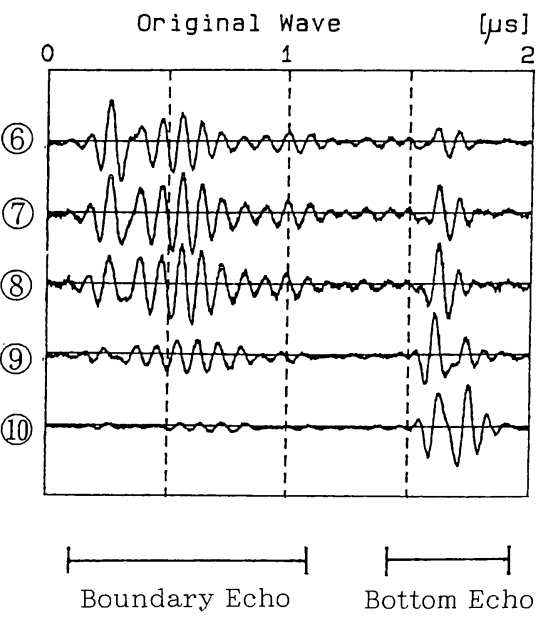

(b)

Fig.20 Measured waveforms of specimen A

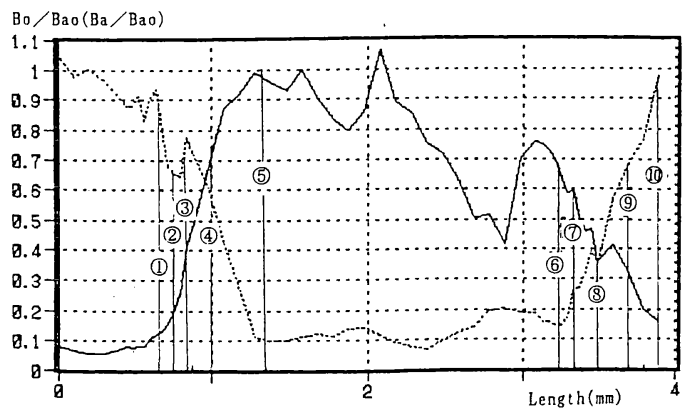

Fig.21 Results of $(\mathrm{Bo} / \mathrm{Bao})$ and $(\mathrm{Ba} / \mathrm{Bao})$ for specimen A

In Fig.20(a) the transition of the received wave from the bottom echo (wave (1), (2)) reflected from the lower surface to the boundary echo (wave (4), (5)) reflected from the defect, when the center of the probe comes into the defect, is clearly shown. And in Fig.20(b) another transition of the received waves from the boundary echo to the bottom echo, when the probe goes out across the defect boundary, is also shown.

In these figures the amplitudes of the waves are normalized by the maximum amplitudes of each waves and the abscissas are scaled by microsecond $(\mu \mathrm{s})$. The numbers shown in Fig.20(a), (b) as (1), (2), etc. indicate the location of the probe where the reflection waves are received and they also correspond to the locations shown in Fig.21.

(2) Results obtained by wave analysis

The reflection wave involves both the boundary echo and the bottom echo, and when the probe comes to be close to the defect boundary the amplitude of boundary echo becomes greater than that of bottom echo. Thus there is a boundary of

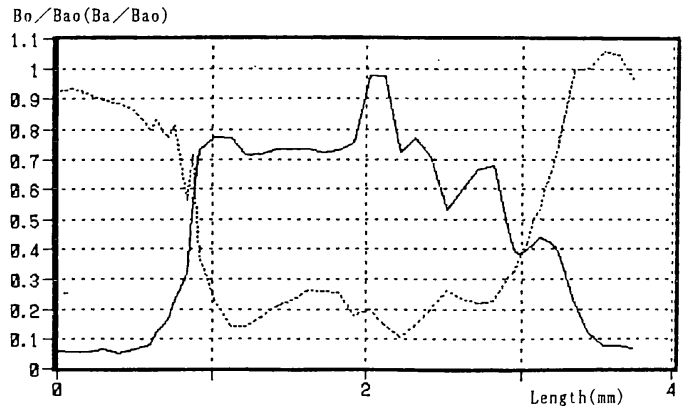

Fig.22 Results of $(\mathrm{Bo} / \mathrm{Bao})$ and $(\mathrm{Ba} / \mathrm{Bao})$ for specimen B

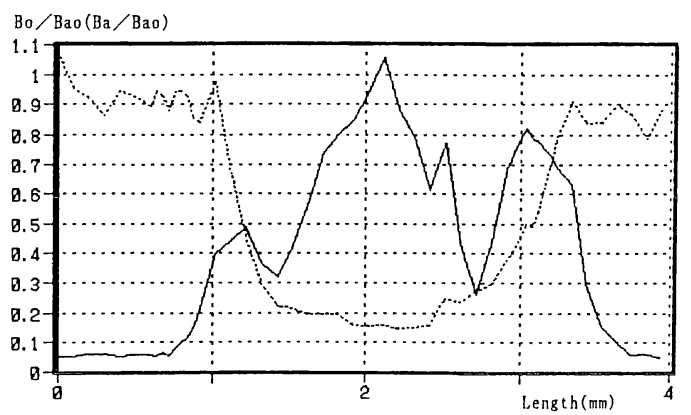

Fig.23 Results of (Bo/Bao) and (Ba/Bao) for specimen C

defect somewhere in the transition range. In the defect image analysis by using the maximum amplitude of the reflection wave we receive the greater amplitude of boundary echo within the area of defect as shown in Fig.20(a), (b) from the wave number (5) to (8). As we can separate the boundary echo from the bottom echo in the reflection wave, we can get each maximum amplitude of both the 
boundary echo (Bo) and bottom echo $(\mathrm{Ba})$. And the normal maximum amplitude of the bottom echo (Bao) is also obtained far from the defect boundary.

The ratios between the maximum amplitude of the boundary echo (Bo) and the normal maximum amplitude of the bottom echo (Bao) are shown in Fig.21, Fig.22 and Fig.23 by the solid lines in the cases of specimen A, B and C, respectively, and the ratios between the maximum amplitude of the bottom echo $(\mathrm{Ba})$ and the normal maximum amplitude of the bottom echo (Bao) are also shown by the dotted lines. The abscissa is scaled by the distance in millimeter $(\mathrm{mm})$.

We can see in three figures that the ratios of $\mathrm{Ba} / \mathrm{Bao}$ become small within the length nearly equal to $2 \mathrm{~mm}$ which correspond to the size of real defect. And the distribution of the ratios of $\mathrm{Bo} / \mathrm{Bao}$ means the undulations of the drilled hole tips because they correspond to the distribution of maximum amplitude of boundary echo. And by the comparison among three results of $\mathrm{Bo} / \mathrm{Bao}$ we can find that if the depth of the defect becomes deeper the $\mathrm{Bo} / \mathrm{Bao}$ values become smaller at the boundary of the defect.

\section{CONCLUSION}

Summarizing the above study on the precise analysis of the reflection wave received by the ultrasonic scanning test to get a improved images of the defect, we have come to the conclusions as follows ;

(1) Twelve C-scan images of defects are obtained by using ultrasonic scanning system together with the path length data which is used to make the defect boundary of image clear.

(2) 3D images of defect shapes are obtained by a CG software on a workstation using both the maximum amplitude data and path length data. We call here this $3 \mathrm{D}$ image as a D scope image.

(3) In order to apply this C-scan measurement of ultrasonic scanning test to the field inspection, the effects of surface roughness and thickness of the specimen on the C-scan image of defect are obtained.

(4) To apply the immersion ultrasonic test to the field inspection we studied the method to use a small water bag between a probe and a specimen and could get the same $\mathrm{C}$-scan image as one given by a usual immersion test.

(5) By a precise waveform analysis of the reflection wave we can obtainthe more accurate defect size given by the distribution of the ratios between the boundary and bottom echo and the normal bottom echo without any scattering effect from the defect.

\section{REFERENCES}

1) Thompson, D.O. and Chimenti, D.E. : Review of progress in quantitative nondestructive evaluation, Plenum Press, Vol.1 (1981) Vol.10 (1991).

2) Miki, C., Fukazawa, M., Katoh, M. and Ohune, H. : Feasibility study on crack detection of fillet welded joint, Proc. of JSCE, No.386, pp.329 337, 1987.(in Japanese)

3) Iijima, T., Hukami, M., Miki, C. and Tajima, J. : Study on fatigue crack detection in stiffening truss chord members, Proc. of JSCE, No.410, I-12, pp.445 454, 1989.(in Japanese)

4) Krautkrämer, J. and Krautkrämer, H. : Ultrasonic Testing of Materials, Springer-Verlag, 1977.

5) Hull, B. and John, V. : Non-Destructive Testing; Macmillan Education, 1988.

6) Mikami, S., Yamazaki, T., Sugawara, N. and Oshima, T. : Study on the improvement of small defect detection for steel structure by means of, ultrasonic pulse echo method, Proc. of The Symposium on Non-Destructive Evaluation in Civil Engineering, JSCE, 1991. (in Japanese)

7) Sugawara, N., Yamazaki, T., Terada, H. and Oshima, T. : Study on the accuracy of defect detection for the images by ultrasonic testing, Proc. of The Hokkaido Branch of JSCE, 1992. (in Japanese)

8) Precision Visuals, Inc. : PV-Wave Overview, 1988.

(Received May 29, 1992)

コンピュータ・グラフィクスと波形解析を応用した超音波探

傷試験の精度向上について

菅原 登・大島俊之.三上修一・杉浦伸哉

本論文では, いくつかの相異なる種類のドリルホールにより作られた欠陥のCスキャ ン画像を求め, この画像におよぼす欠陥の長さや傾きの影響を検討した。

円柱状の人工欠陥は厚さ $9 \mathrm{~mm}$ の鋼板中に直径 $1 \mathrm{~mm}$ と $2 \mathrm{~mm}$ で作られており, 超音 波探傷装置によって得られたエコ一強度データと路程データを，ワークステーション上 のグラフィックソフトウェアを用いて解析することにより 3 次元の欠陥画像を得た。ま た底面エコーと欠陥からのエコーを詳細に波形解析することにより，より精度の良い欠 陥サイズが得られた。ささらに C スキャン超音波探傷法を現場試験に適用するため供試 体の表面凹凸，供試体の厚さなどが探傷結果に及ぼす影響を解析するとともに，水槽を 用いないで水浸法を実現するための簡単な装置による試験を実施した. 